\title{
DEPORTE Y COMUNIDADES AUTÓNOMAS. ASPECTOS COMPETENCIALES DE LA LEY ESTATAL DEL DEPORTE.
}

\author{
José Antonio Razquin lizarraga
}

\begin{abstract}
sumario: I. Introducción.- Il. El Derecho Público del Deporte en la Década 1980-1990. 1. El período transitorio: la ley estatal de 1980 y los primeros desarrollos autonómicos. A. La regulación estatal del deporte: la Ley General de Cultura Física y del Deporte y su desarrollo reglamentario. B. Los traspasos de servicios estatales en materia deportiva. C. La primera reglamentación autonómica: su provisionalidad. 2. Los leyes autonómicas del deporte. 3 . La conservación de competencias estatales sobre Ia materia deportiva. III. LA LeY del Deporte 10/1990 y LAS Comunidades Aurónomas. 1. Una nueva Ley del Deporte. 2. La justificación de la Ley del Deporte. 3. La competencia exclusiva de las Comunidades Autónomas y la ausencia de título competencial expreso del Estado sobre el deporte. 4. La matización de la competencia exclusiva autonómica y la determinación del limitado alcance de la competencia estatal. 5. Análisis de la Ley del Deporte de 1990.- IV. Reflexión Total.
\end{abstract}

\section{INTRODUCCIÓN.}

La notable dimensión social y pública del deporte, expresada en los preámbulos o exposiciones de motivos de la casi totalidad de las disposiciones que abordan o regulan dicha actividad, ha determinado que se admita hoy con naturalidad la intervención pública del deporte, mediante la ordenación pública e intervención administrativa, que parten, y no olvidan, de su dimensión privada. La Constitución Española de 1978, consciente de la importancia del deporte en la sociedad moderna actual, incluye una explícita previsión relativa al mismo, en su capítulo III del título I, relativo a los principios rectores de la política social y económica; expresando de este modo que "el deporte debe empaparse de los principios sustanciales de la Constitución" (1).

El artículo 43.3 de la Constitución dice asi: «3. Los poderes públicos fomentarán la educación sanitaria, la educación física y el deporte. Así mismo facilitarán la adecuada utilización del ocio".

No es éste el momento para entrar en la exégesis de este precepto, cuya ambigüedad, tanto en atención a su efectividad mediata derivada de su ubicación sistemática en el texto constitucional, como por su propia dicción literal («fomentarán»), ha sido señalada por la doctrina

(1) Luis Maria Cazorla Prieto, "Comentario al artículo 43", en Comentarios a la Constitución, (dirigidos por Fernando Garrido Falla), Civitas, Madrid, 2 ed., 1985, p.797.

Véase la excelente sentencia de la Sala 3 del TS de 23 de marzo de 1988 (Aranzadi 1072/ 88), que acoge la mejor y más reciente doctrina sobre el deporte. 
(2). Unicamente indicar que la efectividad directa de tal precepto tendrá lugar en el marco de la legislación que lo desarrolle (3).

No se aborda aquí, pese a su innegable interés, el importante aspecto de la intervención pública del deporte (4) y, más concretamente, la regulación del asociacionismo deportivo, donde parece primar la componente pública sobre la estatuaria (5). Este trabajo se ciñe al aspecto competencial, al reparto competencial entre el Estado y las Comunidades Autónomas sobre la materia deportiva.

El artículo 43.3 no determina el poder público competente para "fomentar" el deporte. Este precepto no es conceptuable cono norma competencial, no es un precepto atributivo de competencias (6).

Para conocer los criterios del reparto de atribuciones entre el Estado

(2) Cfr. José Bermejo Vera, "El marco jurídico del deporte en España", en RAP núm. 110, 1986, pp. 13-15; y del mismo autor "Deportes", en Estudios sobre el Derecho de la Comunidad de Madrid, (Coordinador Rafael Gómez-Ferrer Morant), Civitas, Madrid, 1987. pp. 615-616.

(3) Téngase en cuenta el art. 53.3 de la CE, del tenor siguiente: «El reconocimiento, el respeto y la protección de los principios reconocidos en el capítulo tercero informarán la legislación positiva, la práctica judicial y la actuación de los poderes públicos. Sólo podrán ser alegados ante la Jurisdicción ordinaria de acuerdo con lo que dispongan las leyes que los desarrollen".

(4) Para una perspectiva general sobre el deporte, pueden consultarse, Martin Bassols Coma, "La Administración deportiva: evolución y posible configuración", en RAP núm. 85, 1978, pp.375-390; Luis María Cazorla Prieto, Deporte y Estado, Labor, Barcelona, 1979; José Bermejo Vera, "El marco ...", cit., "Deportes", Cit., Prólogo a la obra de José luis Carretero Leston, Régimen disciplinario en el ordenamiento deportivo español, Diputación Provincial de Málaga y Junta de Andalucia, Málaga, 1985, "Constitución y ordenamiento deportivo", en REDA núm. 63, 1989, pp. 337-364; UNISPORT, EI Derecho deportivo, (recoge las ponencias y comunicaciones de las Jornadas I y II de Derecho Deportivo de 1984 y 1985), Junta de Andalucia, San Fernando, 1986; y Angel Luis Monge Gil, Aspectos Básicos del Ordenamiento Jurídico Deportivo, Diputación General de Aragón, Zaragoza, 1987.

(5) Bermejo Vera, "Deportes", cit., p.627.

Téngase en cuenta la importante STC 67/1985, de 24 de mayo, que resuelve la cuestión de inconstitucionalidad planteada respecto de los arts. 12.2, 14.3 y 15 de la Ley General de la Cultura Fisica y del Deporte, en la que el TC los declara no contrarios a la Constitución desde la perspectiva del derecho constitucional de asociación.

En igual linea se situan las Sentencias de la Sala 3 del TS de 19 de junio de 1984 (Aranzadi 40712) y de 23 de marzo de 1988, que desestiman los recursos interpuestos por el Comité Olimpico Español, la real Federación Española de Fútbol y la Federación Española de Judo y Deportes Asociados, contra el Real Decreto 643/1984, de 28 de marzo, sobre estructuras federativas.

Conforme a esta jurisprudencia, las federaciones deportivas españolas se conforman como asociaciones de configuración legal, a las que el Estado atribuye el ejercicio de funciones públicas de carácter administrativo en un determinado sector de la vida social. Véase el comentario a la citada STC de 24 de mayo de 1985, de José Esteve Pardo, "Las asociaciones de configuración legal. El caso de las Federaciones Deportivas", en REDA núm. 45, 1985, pp. 113-121.

(6) Cfr. STC 15/89, de 26 de enero, con referencia al art. 51 de la Constitución (F.J. 1). 
y las Comunidades Autónomas en materia de deporte, ha de acudirse a las listas de los artículos 148 y 149 de la Constitución.

El artículo 149.1 de la CE no reserva al Estado ninguna competencia expresa en materia de deporte (7). En cambio, el artículo 148.1.19 de la Constitución con una expresión identificable con la del art. 43.3-determina que:

"1. Las Comunidades Autónomas podrán asumir competencias en las siguientes materias: 19 Promoción del deporte y de la adecuada utilización del ocio.

Las Comunidades Autónomas, en sus respectivos Estatutos de Autonomía, han asumido como competencia exclusiva la materia de deportes. Asi, los artículos 10.6 del EAA (competencia exclusiva en materia de "deportes, ocio y esparcimiento"), 11.29 del EAC (competencia exclusiva en materia de "deportes y ocio") y 4.14 de la LORAFNA (competencia exclusiva en materia de "promoción del deporte y de la adecuada utilización del ocion); sin que la diferencia de fórmulas o textos entrañe diversidad competencial, pues en todos los casos se asume como competencia exclusiva la materia de deporte (8).

La asunción como competencia exclusiva de la materia de deporte entraña la facultad de legislar, reglamentar y ejecutar respecto de tal materia, con carácter exclusivo en el respectivo ámbito territorial. Como afirma Alonso García (9), "lo que resulta obvio a partir de la Constitución, es que son las Comunidades Autónomas las llamadas a contemplar el hecho deportivo en su totalidad como fenómeno que permita legislar en todos los aspectos de la política deportiva pública y privada".

Aunque ello parecía comportar la atribución intoto de la disponibilidad ordenadora sobre la materia de deporte por las Comunidades Autónomas, y el correlativo desapoderamiento competencial para el Estado, pronto se trataron de hallar títulos competenciales que amparasen la intervención estatal en esta materia (10).

La reciente promulgación de la Ley 10/1990, de 15 de octubre, del Deporte (11), motiva este trabajo, que parte de la ordenación pública de este sector de la vida social diseñado en dicha Ley;aunque el modelo a

(7) Efectivamente, el art. 149.1 no atribuye ninguna competencia al Estado en la materia: ni legislación básica, ni bases, ni coordinación.

Tal silencio ha sido calificado por Bermejo Vera, "El marco...", cit., p.19, como desafortunado "olvido" del constituyente.

(8) Enrique Alonso Garcia, "Las competencias de los entes locales en materia de deporte", en Tratado de Derecho municipal, (director Santiago Muñoz Machado), Civitas, Madrid, 1988, II, p. 1795, nota 54.

(9) op. cit., p. 1383.

(10) Bermejo Vera, "El marco...", cit., pp. 19-20; Alonso Garcia, op. cit., pp. 1377-1395.

(11) BOE núm.249, de 17 de octubre de 1990. 
trazar bien pudo ser distinto, incluso profundizando más en la vertiente de descentralización política a que impulsa nuestra Ley Fundamental, ya que aquel no es el único constitucionalmente posible (12).

\section{EL DERECHO PÚBLICO DEL DEPORTE EN LA DÉCADA 1980-1990.}

1. El periodo transitorio: la ley estatal de 1980 y los primeros desarrollos autonómicos.

El período 1979-1985 (desde la Constitución a las primeras leyes autonómicas del deporte) puede resumirse en tres datos:

\section{A. La regulación estatal del deporte: la Ley General de Cultura Física y del Deporte y su desarrollo reglamentario.}

Aún sin aprobarse la mayoría de los Estatutos de Autonomía,el Estado procedió a la ordenación del deporte mediante el dictado de la Ley 13/1980, de 31 de marzo, General Física y del Deporte.

Una Ley que, sin aludir a un título competencial del Estado (13), reguló con carácter general y global la materia de deporte, imponiendo sus criterios o principios básicos a las Comunidades Autónomas (artículo 3.3).

La Ley de 1980 ha sido calificada por la mejor doctrina que se ha ocupado de lo que podríamos llamar Derecho público del deporte, como una ley prearmonizador (14), como una anomalía jurídica, desde la

(12) La Ley del Deporte pretende dentro de los parámetros de delimitación competencial deducibles de la doctrina del Tribunal Constitucional.

Sobre los problemas que suscita esa doctrina constitucional y su necesaria revisión para recobrar el inicial espíritu estatuario y sentar unos criterios objetivos que conlleven cierta seguridad jurídica en cuanto al reparto competencial, véanse los espléndidos trabajos de Luis López Guerra, "Conflictos competenciales, interés general y decisión política", en Revista del Centro de Estudios Constitucionales, núm. 1, 1988, pp. 77-92; y de Carles Viver I PI-SUNYER, "Soberanía, autonomía, interés general ... y el retorno del jurista persa», en RVAP, núm. 25, 1989 , pp. 77-101.

(13) La Ley, más preocupada por justificar el intervencionismo público en el ámbito del deporte que la misma realiza con fundamento en el artículo 43.3, se limita en su exposición de motivos a señalar como principio básico de la misma:»la competencia del estado en su misión de fomentar la educación física y el deporte, sin perjuicio de las competencias de las Comunidades Autónomas y de las Corporaciones Locales en la promoción deportiva".

(14) Bermejo Vera, "El marco...», cit., p. 20. 
óptica constitucional (15). Sin embargo, esta Ley no fue recurrida por las Comunidades Autónomas (16).

El desarrollo reglamentario de la Ley (en el que destacan tres aspectos importantes: la reglamentación del régimen disciplinario deportivo; la regulación del cauce asociativo, de los clubs, agrupaciones $y$ estructuras federativas; y las normas sobre actividades y representaciones deportivas internacionales (17), inicialmente (19801982) en línea con el criterio amplio de ésta, trató ulteriormente (1984) de aclarar o corregir ese criterio expansivo, ciñendo la competencia del Estado al deporte competitivo supraterritorial o supracomunitario, a las competiciones de carácter nacional e internacional (18).

\section{B. Los traspasos de servicios estatales en materia deportiva.}

Los Reales Decretos de transferencias de servicios a las Comunidades Autónomas en materia de deportes son el trasunto de los criterios de la Ley de 1980; pues, tras reconocer la competencia exclusiva en la materia de aquéllas, diseñan un sistema competencial compartido y concurrente entre las mismas y el Estado (19).

C. La primera reglamentación autonómica: su provisionalidad.

La singularidad del fenómeno deportivo y el enraizamiento de un concreto modelo de estructuras asociativas motiva que las primera regulaciones autonómicas en materia deportiva, que ven la luz en este

(15) Alonso Garcia, op. cit., p. 1380.

(16) Según Bermejo Vera, "El marco...", cit., p. 20, ha sido una Ley comprendida $y$ comprensible por las Comunidades Autónomas.(17) El Real Decreto 2075/1982, de 9 de julio, de normas sobre actividades y representaciones deportivas internacionales, fue objeto de conflicto de competencias y de recurso contencioso-administrativo por el Consejo Ejecutivo de la Generalidad de Cataluña. El primero fue resuelto por la STC 1/1986, de 10 de enero, en el sentido de entender que sus arts. 1, 3, 4 y 5 no menoscaban las competencias que en materia deportiva corresponden estatuariamente a la Generalidad. Y el segundo fue desestimado por la Sentencia de la Sala 3 del TS de 29 de diciembre de 1986 (Aranzadi 7707/86).

(18) A fin de respetar «las competencias propias de las Comunidades Autónomas en el ámbito del deporte, sin menoscabo de las atribuciones del Estado para la regulación y aplicación de las normas que atienden al normal desarrollo del deporte competitivo supraterritorial" (en palabras del preámbulo del Real Decreto 642/84 de 28 de marzo, de reglamento de disciplina deportiva); o para aclarar algunas dudas en relación con el reparto competencial generadas por disposiciones reglamentarias anteriores (preámbulo del Real Decreto 643/84, de 28 de marzo, de estructuras federativas deportivas españolas).

Pese a ello, tales disposiciones afectan al ámbito territorial autonómico (cfr. artículo 7 del reglamento de disciplina deportiva, relativo a la competencia disciplinaria de las organizaciones federativas de ámbito territorial).

(19) Véase, por todos, el Real Decreto 2434/82, de 24 de julio, de traspaso de funciones y servicios del Estado a la Junta de Galicia en materia de cultura (BOE núm. 235, de 1 de octubre de 1982). 
período (1980-1985), acepten el esquema de ordenación deportiva, tanto competencial como sustantivo, existente a nivel del Estado.

Los distintos decretos autonómicos reguladores de las federaciones deportivas territoriales o autonómicas (20) se caracterizan por las siguientes notas:

a) Aceptación del marco competencial y sustantivo contenido en la Ley $13 / 80$, General de Cultura Física y del Deporte.

b) Creación de federaciones autonómicas o territoriales propias, con personalidad jurídica propia.

c) Pese a lo anterior, integración obligada de las federaciones deportivas autonómicas en la Federación española correspondiente.

De este modo parecen invertirse los términos en que la cuestión está planteada desde la perspectiva competencial: el Estado se erige en regulador general y ordenador global del deporte; y las comunidades Autónomas, "los Entes llamados por la constitución a desarrollar por excelencia la política deportiva (21), no sólo aceptan el contenido de la Ley estatal, sino que limitan el ejercicio de su competencia a regulaciones puntuales de la materia, de carácter reglamentario, en desarrollo de los criterios establecidos por la norma legal estatal.

Pero esta fase debe considerarse provisional, al menos desde la perspectiva autonómica, por cuanto que las distintas disposiciones autonómicas matizan que tales regulaciones reglamentarias lo son «sin perjuicio de una futura ordenación general del deporte a través de la norma legal correspondiente" (22).

\section{Las leyes autonómicas del deporte.}

Ese transitorio estadio se cierra con la promulgación por las Comunidades Autónomas de las leyes aautonómicas reguladoras del deporte. Son ya cuatro las Comunidades Autónomas que han dictado sus respectivas leyes de deporte (23).

(20) Andalucia (Decreto 146/85, de 26 de junio, por el que se regula la constitución, estructuras y fines de las federaciones andaluzas de deporte); Aragón (Decreto 56/1984, de 30 de julio, por el que se regulan las federaciones deportivas aragonesas); Cantabria (Decreto 74/1983, de 6 de diciembre, por el que se regula la actividad de las asociaciones y federaciones deportivas en territorio de Cantabria); Galicia (Decreto 116/83, de 27 de junio, regulando la constitución y funcionamiento de las federaciones deportivas gallegas); Navarra (Decreto Foral 134/1984, de 16 de mayo, de Federaciones Deportivas de Navarra); y Valencia (Decreto 120/84, de 12 de noviembre, por el que se regula la constitución y funcionamiento de las federaciones deportivas valencianas).

(21) Alonso Garcia, op. cit., p. 1395.

(22) Por todos, el Derecho de la Diputación General de Aragón 56/1984, de 30 de julio.

(23) Castilla y León (hoy, Ley $9 / 1990$, de 22 de junio de Educación física y deportes); Madrid (Ley 2/1986, de 5 de junio, de cultura fisica y el deporte); y País Vasco (Ley 5/1988, de 19 de febrero, de la cultura física y el deporte). 
Estas leyes autonómicas desarrollan el mandato del art. 43.3 de la CE en una línea de intervención pública del deporte pretendidamente equilibrada con su dimensión o componente privado $y$, sobre todo, operan un replanteamiento de los Reales Decretos de Transferencias (24) y del esquema provisional de ordenación autonómica del deporte referidos más arriba.

A pesar de su diversidad, y al objeto aqui interesado, puede reflejarse un denominador común a todas ellas, expresado en los siguientes aspectos:

a) Llevan a cabo la ordenación del deporte en el ámbito territorial correspondiente con criterios de generalidad, globalidad y plenitud. Las leyes autonómicas tratan de diseñar, en cada caso, una política autonómica propia en la materia, sin cita ni remisión ahora a los principios y contenido de la legislación estatal del deporte.

b) Uno de los aspectos básicos regulado por las leyes autonómicas es el relativo al asociacionismo deportivo.

Las federaciones autonómicas se configuran como asociaciones con personalidad jurídica y con competencia plena en el ámbito territorial correspondiente. Con alguna excepción más formal que real, se traslada el modelo estatal federativo (25): las federaciones son asociaciones de configuración legal y sólo se permite una única federación autonómica por cada modalidad deportiva (26). Asimismo, aunque con fórmulas dispares, prevén su integración en las Federaciones deportivas estatales correspondientes (27).

El punto de conexión competencial para la regulación de los clubs y asociaciones deportivas es el asociativo, sin perjuicio de que cuando los clubs y entidades afiliados a las federaciones autonómicas intervengan en competiciones de ámbito estatal o internacional se sujetan en materia disciplinaria y competitiva a las normas y reglamentos de las federaciones deportivas españolas e internacionales.

(24) Bermejo Vera, "Deportes", cit., p. 617, con referencia a la Comunidad Autónoma de Madrid.

(25) Como señala Bermejo Vera, "Deportes", cit., p. 629, "la federación es la fórmula tradicional del asociacionismo deportivo de segundo grado". 630.

(26) Véase con referencia a la Ley madrileña, Bermejo Vera, "Deportes", cit., pp. 629-

(27) La Ley catalana (artículo 19.1) determina que "las federaciones deportivas catalanas, a efectos de su participación en la actividad deportiva de ámbito estatal, deberán formar parte de las federaciones españolas en la representación que corresponda"; y la Ley vasca (artículo 35.7) se limita a señalar que la federación vasca de cada modalidad deportiva será la representante en el ámbito estatal de sus deportistas, clubes, agrupaciones, técnicos y jueces, $y$, según el procedimiento reglamentario que se establezca, regulará la designación de sus representantes entre los miembros electos de su asamblea". A la integración obligada apunta el art. 34.2 de la Ley 9/1990 de Castilla-León. Nada dice, en cambio, sobre este extremo la Ley madrileña (cfr. artículos 11 a 14). 
Por su parte, la Ley vasca 5/1988 configura las autorizaciones, licencias y habilitaciones federativas para el deporte con carácter autonómico, con la sola exigencia de comunicación y, en su caso, inscripción, en los registros estatales para la participación en competiciones en el ámbito estatal (28).

c) Se incluyen dentro de la competencia autonómica, el deporte de alto nivel y las instalaciones deportivas -que son objeto de regulación(29), sin limitarse al denominado "deporte para todos".

3. La conservación de competencias estatales sobre la materia deportiva.

De este rápido repaso a la situación anterior a la Ley del Deporte, se alcanza una fácil conclusión:

a) El ejercicio por las Comunidades Autónomas de facultades legislativas en materia de deporte mediante la aprobación de leyes autonómicas que regulan de modo global y general, con criterio de complitud, el deporte en el ámbito territorial respectivo.

b) La coexistencia de esta legislación autonómica con una legislación estatal también reguladora del deporte. A pesar del silencio de la artículo 149.1 de la CE en cuanto al deporte, subsiste el ejercicio de facultades estatales sobre la materia deportiva, en base a títulos competenciales diversos al específico en esa materia.

Ambos ámbitos competenciales, el autonómico y el estatal, no pueden configurarse con un criterio de separación o fragmentación, por razón competencial, de un sector de la vida social que también debe atender a $\mathrm{u}$ orden material a alcanzar.

\section{LA LEY DEL DEPORTE 10/1990 Y LAS COMUNIDADES AUTÓNOMAS.}

\section{Una nueva Ley del Deporte.}

Las insuficiencias de la Ley General de Cultura Fisica y del Deporte

(28) Su artículo 32.4 dispone que "de los actos de inscripción de los clubs de la comunidad autónoma se dará traslado a los Registros deportivos dependientes de los órganos del Estado, a efectos de información y publicidad"; $y$, por otra parte, su artículo 37.2 y 3 dispone que " 2 . Las federaciones vascas son las entidades competentes de la comunidad autónoma para emitir las licencias federativas que permitan competir en su modalidad deportiva" y " 3 . Las licencias que las federaciones vascas emitan habilitarán a todos sus estamentos deportivos a competir en el ámbito estatal. Las federaciones vascas darán traslado a las federaciones estatales de los extractos de las licencias por ellas emitidas".

(29) Arts. 46 y 50 a 62 de la Ley catalana; y 18 a 21 y 22 a 27 de la Ley vasca. 
de 1980 (30) han motivado su sustitución por una nueva Ley del Deporte, la Ley 10/1990, de 15 de octubre.

La Ley del Deporte comienza reconociendo la importancia del hecho autonómico como una de las causas que ha motivado el cambio del modelo deportivo en España con referencia al existente en el momento de la aprobación de la Ley de 1980 (31).

De ahí que la Ley del Deporte, desde este prima de las competencias de las Comunidades Autónomas, realice una rectificación parcial de la Ley de 1980 en dos aspectos:

a) De un lado, la nueva Ley del Deporte justifica en su preámbulo la concurrencia de un título competencial del Estado para su dictado (32).

b) Y; de otro, la Ley pierde su carácter general y global. Su alcance es limitado, puesto que su objetivo fundamental -a decir de su preámbulo"es regular el marco jurídico en que debe desenvolverse la práctica deportiva en el ámbito del Estado"; es decir, se ciñe a la faceta supraautonómica, a la faceta competitiva de ámbito estatal e internacional (33).

(30) Estas insuficiencias, expresadas en la memoria del proyecto de Ley del deporte son, de manera escueta, las siguientes:

"-Falta de separación clara entre el sector público y el sector privado de la organización deportiva.

- Existencia de una fórmula de asociacionismo deportivo que se ha mostrado muy poco operativa.

- Ambigüedad a la hora de definir las federaciones deportivas españolas y falta de requisitos de control para el ejercicio de competencias de carácter público.

- Falta de un régimen disciplinario suficientemente desarrollado en la propia ley.

- Inexistencia de un tratamiento específico de determinados aspectos que hoy en dia, y en el futuro, son de vital importancia en el mundo del deporte: el deporte de alto nivel, el consumo de sustancias prohibidas y la utilización de métodos ilegales, las titulaciones deportivas, la investigación, las instalaciones deportivas...".

(31) "Las Comunidades Autónomas -a decir de la memoria-, sin exclusión, han asumido su plena competencia en la organización del deporte en su ámbito territorial, y eso obliga a una redistribución de las competencias de las diferentes administraciones en favor de una mayor descentralización. Esta descentralización a dado resultados positivos en el aumento de la base deportiva del pais, y está permitiendo al Consejo Superior de Deportes, ya en estos momentos, un trabajo más específico y de mayor calidad en aquellas responsabilidades del estado que le son propias".

Y, a tenor del preámbulo de la Ley, la sustitución de la Ley de 1980 se debe a las "exigencias derivadas de la interpretación pautada del proceso autonómico, y por propia evolución del fenómeno deportivo".

(32) A nadie se le oculta el peligro de que bajo esta técnica de justificación competencial en los preámbulos se pretenda ampliar el correspondiente ámbito competencial, distorsionando el sistema de delimitación de competencias.

Cfr. el Dictamen del Consejo Ejecutivo de la Generalidad de Cataluña núm. 79, de 23 de octubre de 1984, sobre la Ley estatal 33/1984, de ordenación de los seguros privados, F.J. II (en Dictámenes 1984, Barcelona, 1986, pp. 346-347.

(33) Debe señalarse, por otra parte, que no comprende la educación física, a excepción de una declaración.general al respecto (art.3). 
Habida cuenta de que el Estado promulga una Ley del Deporte, es preciso analizar si concurre nos hallaremos ante una ley de armonización, dictada al margen de la previsión constitucional del artículo 150.3 (34).

2. La justificación de la titularidad competencial del Estado en la doctrina y en la nueva Ley del Deporte.

La doctrina, consciente de la importancia del fenómeno deportivo en la sociedad actual y de su creciente internacionalización, pronto se ocupó de colmar el silencio constitucional, la ausencia en la Carta Magna de un expreso y específico título competencial en materia de deporte en favor del Estado.

Para el profesor Bermejo Vera (35), son varios los principios y razones que justifican la potestad del Estado en la materia deportiva; a su entender, los siguientes:

a) El deporte no es una "materia" formal y sustantivamente susceptible, asignable como "contenido inherente" a uno u otro ámbito competencial. El deporte carece de un contenido monolítico que permita su encaje en un título competencial establecido por la Constitución, como ocurre en otras materias (turismo, competencia del consumidor, etc.).

b) La exclusividad es un término equívoco. Se trata de una exclusividad relativa si sea tiende a los límites territorial y personal de las competencias autonómicas (36).

c) El deporte es una manifestación de la cultura,'por lo que entra en juego la competencia concurrente del art. 149.2 de la CE., "aunque sólo sea para posibilitar la necesaria comunicación entre las distintas Comunidades <<espacialmente>> competentes".

d) El título de relaciones internacionales del art. 149.1.3. de la CE. (37).

En opinión de este autor, ello resulta acreditado por la Ley de 1980, que no ha sido recurrida por las Comunidades Autónomas. Actitud

(34) La Constitución prevé distintas categorías de leyes con justificación, finalidad, contenido, y procedimiento de elaboración diversos. A decir de la STC 132/1989, de 18 de julio, (F.J. 22), es distinta la naturaleza de ambas Instituciones, bases (aquí, además, legislación directamente aplicable no básica) y armonización, pues son manifestaciones distintas. La armonización "puede incidir, según lo dispuesto en el art. 150.3 de la Constitución, cobre competencias de las Comunidades Autónomas y se trata de una intervención normativa excepcional, según lo establecido por este Tribunal en su STC 76/ 1983 , fundamento jurídico $3^{\circ}$ ". En cambio, el primer supuesto considerado "se justifica en el ejercicio ordinario de una competencia estatal».

(35) "El marco ...", cit., pp. 19-20.

(36) También Alonso Garcia, op. cit., p. 1381, alude al criterio territorial, al reconocer la competencia del Estado respecto del "asociacionismo a nivel supracomunitario".

(37) En igual sentido, Alonso Garcia, op. cit., p. 1381, cita este título competencial. 
laudable de éstas, "tal vez conscientes de la razonalidad de la $<<$ naturaleza de las cosas $>$, y no debe, por eso mismo, ser aprovechada desde la instancia estatal para interferir a perpetuo una situación bien endeble en una estricta hermenéutica constitucional" (38). La Ley de 1980 es calificada por este autor como una "disposición legislativa prearmonizadora comprensible y comprendida" (39).

La nueva Ley del Deporte ha acogido sustancialmente estas consideraciones. A tenor de su preámbulo dos son las razones que justifican tal ejercicio de la potestad legislativa por el Estado. En primer lugar, el criterio territorial limitado de las Comunidades Autónomas, de donde se deriva que "la faceta competitiva de ámbito estatal e internacional que es inherente al deporte justifica la actuación del Estado".

$y$, en segundo lugar, la incidencia de una pluralidad de títulos competenciales sobre la materia del deporte, como son la consideración de la actividad deportiva como manifestación cultural y otros títulos específicos de educación, investigación, sanidad o legislación mercantil que avalan la actuación estatal en la materia, "en su faceta supraautonómica".

De este modo la justificación principal está constituída por el criterio territorial, que constituye no sólo el primer motivo de justificación, sino que impregna expresamente a la segunda razón.

Así resulta de la STC 1/1986, de 10 de enero (F.J. 3)-parcialmente transcrita en el preámbulo de la Ley-, que remite al criterio territorial, pero solamente con referencia a las federaciones, excluyendo la referencia -por quedar fuera del objeto del proceso- a los clubes (F.J. 1) (40). Esta STC (F.J. 3) dice asi:

"Pues si ésta (la Comunidad Autónoma) tiene, sin duda, competencias en materia deportiva con arreglo a un Estatuto de Autonomía, no es menos cierto que estas competencias, como cualesquiera otras de las que ostente, no pueden desplegarse sobre entes que, como en este caso ocurre, existen y desarrollan sus actividades en un ámbito nacional sustraído ya en el ejercicio de las potestades autonómicas, estando la autonomía constitucionalmente garantizada a las Comunidades Autónomas, al servicio de la gestión de sus intereses propios (art. 137 $\mathrm{CE}$ ), limitados ratione loci (art. 25.1 EAC), y no siendo desde ella posible,

(38) Bermejo Vera, "El marco ...", cit., p. 20.

(39) Ibidem, p. 20.

(40) Esta STC desestima el conflicto positivo de competencia promovido por el Consejo Ejecutivo de la Generalidad de Cataluña frente a distintos preceptos del Real Decreto 2075/1982, de 9 de julio, de normas sobre actividades y representaciones deportivas internacionales. 
ciertamente, la afectación (...) de intereses que son propios del deporte federado español en su conjunto".

En consecuencia, el criterio territorial justifica la intervención del Estado. El territorio, límite inherente a las competencias de las Comunidades Autónomas, se transforma en fundamentador de la competencia estatal.

3. La competencia exclusiva de las Comunidades Autónomas y la ausencia de título competencial expreso del Estado sobre el deporte.

Para examinar las distintas razones que pretendidamente avalan la existencia de título o títulos competenciales del Estado sobre la materia deportiva, ha de partirse de la delimitación competencial establecida en la Constitución y en los Estatutos de Autonomía, a la que escuetamente se ha aludido más arriba.

Las Comunidades Autónomas-todas ellas- han asumido, en virtud de sus Estatutos, "la totalidad de la competencia exclusiva sobre la materia deportiva" (41).

No es preciso referir ni ahondar aquí en el debate doctrinal sobre el concepto y significado de las "competencias exclusivas" (42), calificación o adjetivo utilizado con sentido marcadamente equívoco tanto en la Constitución como en los Estatutos según el Tribunal Constitucional (43), dado que nos hallamos ante un supuesto, la materia deportiva, en el que las Comunidades Autónomas asumen la totalidad de las potestades sobre dicha materia. Lo que conlleva que las Comunidades no sólo ostentan en su territorio todas las potestades públicas (legislativa, reglamentaria y de ejecución) (44), sino además que en el territorio autónomo ningún otro poder público puede ejercer estas mismas potestades sobre la misma materia, esto es, la atribución plena y total a las autonomías conlleva el correlativo desapoderamiento al Estado de

(41) Alonso Garcia, op. cit., p. 1381, nota 17.

En contra, Monge Gil, op. cit., p. 58, sostiene que «el deporte no es competencia exclusiva ni del Estado ni de as Comunidades Autónomas".

(42) Por todos, Santiago Muñoz Machado, Derecho Público de las Comunidades Autónomas, Civitas, Madrid, 1982, I, pp. 357-367. También Avelino Blasco, «Sobre el concepto de competencias exclusivas", en REDA núm. 29, 1981, pp. 307-317.

(43) STC 37/1981, de 16 de noviembre; y 5/1982, de 8 de febrero.

(44) En palabras de la STC 86/89, de 11 de mayo (F.J. 7), cuando nos hallamos ante una materia no incluida en el art. 149.1 C.E. y sí exclusiva de las Comunidades Autónomas (como en el caso del deporte) "se trata de una competencia efectivamente exclusiva stricto sensu, comprendiendo la potestad legislativa y abarcando toda la materia, no simplemente el desarrollo de las bases estatales". Sin olvidar que, como continúa diciendo esta sentencia, "dicha competencia debe entenderse inserta dentro del marco constitucional, del que pueden derivarse limitaciones expresas o explícitas; limites a respetarn. 
esas facultades dentro del territorio autonómico.

Se trata así de una competencia exclusiva de las Comunidades Autónomas, es decir, excluyente y monopolizada, lo que significa que sólo el titular de la competencia puede producir normas válidas (45).

La primera razón aportada por la doctrina (la no configuración del deporte como materia a efectos competenciales) es desmentida por el propio texto constitucional (cfr. art. 148.1.19) o bien se conecta directamente con la última de ellas, esto es, apela a la "naturaleza de las cosas", argumento éste último ya desechado por el Tribunal constitucional (46).

El recurso al art. 149.2. pudiera ser, en principio, discutible por prevalecer el título específico "deporte" sobre el genérico de "cultura" (47); $y$, en otro caso, determinadas manifestaciones deportivas se insertan en el título competencial de "espectáculos", materia también atribuída constitucional y estatuariamente a la competencia exclusiva de las Comunidades Autónomas (48).

Con ello, y dejando de lado otros títulos específicos colaterales, el argumento básico en favor de una titularidad competencial del Estado sobre el deporte es el criterio territorial; esto es, el límite territorial inherente a las competencias autonómicas (49) deja un reducto, la faceta supraautonómica tanto nacional como internacional, que puede ser ocupado por el estado. Argumento que abordaremos más adelante por constituir la justificación nuclear en que se apoya la Ley.

(45) Muñoz Machado, op. cit., l, p. 365.

(46) A decir de la STC 75/1989, de 21 de abril (F.J. 2), "no cabe justificar una competencia estatal por la mera razonabilidad de la medida, ni la por conveniencia de adoptar estas medidas a nivel <<supraautonómico >, ya que la persecución del <<interés general > que representa el Estado <<se ha de materializar'a través de', no 'a pesar de' los sistemas de reparto de competencias articulados en la Constitución >> (STC 146/1986, de 25 de noviembre), excluyéndose asi que el ámbito de competencias autonómicas pueda ser extendido por meras consideraciones finalisticas".

(47) La STC 87/1987, de 2 de junio (F.J. 2), declara «la prevalencia de la regla competencial especifica sobre las más genéricas". (F.J. 6).

Sobre el sentido de la regla del art. 149.2 de la CE, véase la STC 49/1984, de 5 de abril

(48) A tal efecto cfr. las SSTC 143/85, de 24 de octubre; y 149/85, de 5 de noviembre.

(49) Según la STC 88/1989, de 11 de mayo, F.J. 3, el ámbito territorial es uno de los elementos determinantes de la competencia autonómica: "la conexión territorial de las competencias se incorpora a cada norma atributiva contenida en el Estatuto delimitando su supuesto de hecho y condicionando espacialmente la habilitación que otorga".

Señala Bermejo Vera, "Deportes", cit., p. 620, con referencia al art. 1 de la Ley madrileña, que "está en directa conexión con el <<ámbito de la Comunidad de Madrid»>, cuya concreción en lo que al deporte se refiere no va a ser nunca demasiado fácil. En términos generales, habría que decir que dicho ámbito se refiere al espacio territorial madrileño y al conjunto competencial asignado a los órganos de la Comunidad en materia de deporte, ambos aspectos indisolublemente unidos". 
El parangón de la competencia autonómica sobre la materia deportiva con la también exclusiva de "turismo", nos permite traer a colación la doctrina establecida por la STC 75/89, de 21 de abril, al efecto. A tenor de esta sentencia (F.J. 3) "el Estado no está legitimado para fomentar cualquier actividad en materia de turismo, ni tiene una competencia general $\mathrm{e}$ indeterminada de fomento del turismo paralela o concurrente con las competencias asumidas por las Comunidades Autónomas, pues ello significaría no sólo alterar el sistema competencial, sino también distorsionar de forma permanente el sistema ordinario de financiación autonómica".

Una última consideración a recordar. Aunque sea posible el entrecruzamiento de títulos competenciales (títulos horizontales, transversales o colaterales sobre la actividad deportiva), que pudieran limitar la competencia exclusiva autonómica, puesto que ésta debe entenderse dentro del marco constitucional; para determinar en cada caso cuál sea el prevalente, es presupuesto inexcusable la concurrencia de un concreto título competencial del Estado. No se puede apelar a la "naturaleza de las cosas", ni al interés general, sino que ha de aportarse caso por caso un explícito título competencial (50).

4. La matización de la competencia exclusiva autonómica y la determinación del limitado alcance de la competencia estatal.

Cuanto llevamos expuesto pudiera conducir aparentemente a la negación de cualquier título competencial del Estado sobre la materia deportiva, con la salvedad de algunos aspectos puntuales como serian las normas que la Ley expresa al amparo de distintas reglas del art. 149.1 (Disposiciones Adicionales 2 y 4,1). Sin embargo, no se trata de desapoderar al Estado de toda facultad de actuación respecto del deporte ni de proscribir su intervención respecto de las actividades deportivas; postura que supondria negar cualquier cobertura constitucional a la Ley.

No cabe duda de que la realidad no es compartimentable de modo estricto $y$, además, estamos asistiendo a la creciente internacionalización del deporte. Existe una realidad deportiva, la faceta competitiva de ámbito estatal e internacional que no puede ser desconocida ni olvidada; faceta, por otra parte, que supera el ámbito competencial de las Comunidades Autónomas acotado a su propio territorio.

Ello lleva a matizar la competencia exclusiva de las Comunidades Autónomas sobre la materia deportiva en un doble sentido (51):

(50) El Tribunal Constitucional ha exigido siempre un titulo competencial concreto para la intervención estatal (SSTC 15/1989 y 75/1989).

(51) Cfr. los Dictámenes del Consejo Consultivo de la Generalidad de Cataluña núm. 30, de 13 de octubre de 1982, en relación con el Real Decreto 2075/1982, sobre actividades y representaciones deportivas internacionales (Dictámenes 1984, pp. 450-456); y núm. 144, de 15 de marzo de 1988, sobre el Proyecto de Ley del Deporte de Cataluña (Dictámenes 1988, pp. 113-150), cuya calidad y objetividad son dignas de encomio. Mi postura coincide con la tesis expresada en dichos dictámenes. 
a) El limite territorial de las competencias autonómicas se compatibiliza con las competencias del Estado respecto de las actividades deportivas de carácter estatal e internacional, competencias que pueden encontrar cobertura, de una parte,-a falta de título competencial expresoen el artículo 149.2 de la $C E$, ya que el deporte puede encuadrarse en el concepto más amplio de cultura (52), y, de otra, en el artículo 149.1.3.

b) Las peculiaridades del fenómeno deportivo motivan la proyección de distintos títulos competenciales sobre la materia deportiva; títulos algunos de ellos atribuídos al Estado por el artículo 149.1 (como son sus apartados 3,29 y 30 ). Y, en especial, las reglas de reparto competencial en materia de asociaciones.

Para cohonestar las competencias exclusivas de las Comunidades Autónomas sobre la materia deportiva, de un lado, y la ordenación de la faceta competitiva estatal e internacional, de otro, ha de complementarse la dialéctica competencial con una perspectiva de coordinación participativa de las distintas instancias, que impida la separación y fragmentación de la actividad deportiva, muchas de cuyas manifestaciones se constituyen a modo de sistema, con carácter unitario que no puede ser desconocido.

Ha señalado Parejo Alfonso (53), que debe entenderse superada la etapa "constructivista" del Estado de las Autonomias en la que se ha enfatizado el instrumento competencial, con el consiguiente peligro de un modelo de "excesiva fragmentación del poder sin mecanismos compensatorios adecuados", para pasar a un nuevo estadio en que primen los criterios de colaboración u cooperación, a los que reiteradamente llama el Tribunal Constitucional cada vez con más insistencia, por cuanto que "el Estado Autonómico descansa sobre no sólo la no contradicción de la división territorial del poder con un mínimo orden constitucional material, sino incluso la adecuación de ésta para la eficaz realización del mismo, al igual que la división funcional del poder (interna a cada nivel territorial) no impide y sí favorece el correcto ejercicio del poder públicon. Un nuevo estadio de integración participativa, que tienda más a "determinar el modo de alcanzar y producir normas y decisiones materialmente correctas" (54) y que "supone (más allá de la

(52) En este sentido se pronuncia la STC 1/1986, de 10 de enero.

(53) «El Gobierno de la Nación y los Gobiernos de las Autonomías territoriales; un problema de articulación", en DA, núm. 215, 1988, pp. 146-159.

(54) La razón justificativa que da Parejo Alfonso, Ibidem, p. 151, es trasladable al campo del deporte: «ni la compleja realidad de la vida social es reductible y, por tanto, reproducible fielmente por un esquema de reparto de competencias, ni éste puede desarrollarse de forma tan perfecta que, en el momento normativo previo, logre prever todas las hipótesis posibles presentes y futuras". 
sola justificación competencial) la participación o intervención, en lo necesario, de las Comunidades Autónomas en la formación de la voluntad de los órganos o instituciones del poder central" (55).

Esa reflexión, aunque de ámbito más general, pudiera traspasarse al campo de la materia deportiva para coordinar la competencia exclusiva de las Comunidades Autónomas y la existencia de competiciones de ámbito estatal e internacional (56). No puede olvidarse tampoco la disparidad de manifestaciones que cubre el deporte, cuya pluralidad impide una "equivocada concepción unitaria (57).

De este modo la intervención estatal en materia deportiva se presenta con un alcance y contenido limitados. La competencia del Estado se ciñe a las actividades deportivas de carácter estatal e internacional, comprendiendo en ello la estructura federativa española (58).

No cabe duda de que el aspecto más conflictivo desde la perspectiva competencial es el relativo al asociacionismo deportivo (59), cuya importancia como "auténtico punto de apoyo de las actividades deportivas" (60) es unánimemente reconocida y destacada.

Dejando al margen el desarrollo orgánico del derecho de asociación (arts. 22 y 149.1.1 de la CE), las Comunidades Autónomas han asumido la competencia exclusiva en materia de asociaciones culturales "que ejerzan principalmente sus funciones" en su territorio (61). Lo que plantea cual sea el orden competencial en este concreto aspecto del asociacionismo deportivo.

A mi entender, la competencia exclusiva de las Comunidades Autónomas en materias de deporte y de asociaciones culturales que desarrollen principalmente sus funciones en su territorio les dora de la

(55) lbidem, pp. 156-157.

(56) A ello parece apuntar Bermejo Vera con su implícita llamada a la prudencia en una futura ordenación estatal del deporte («El marco ..., cit. p. 20).

En parecido sentido, Monge Gil, op. cit., p. 59, cree "que una postura conciliadora, presidida por las ideas de colaboración y coordinación, resulta más prudente para entender unas relaciones entre dos órdenes territoriales <<condenados al entendimiento $\gg »$.

(57) Monge Gil, op. cit., p. 22.

La propia Ley del Deporte, y las leyes autonómicas, reflejan la pluralidad y diversidad de manifestaciones del deporte, que impiden su consideración unívoca.

(58) Señala Monge Gil, op. cit., p. 64, que el Estado debe recabar el mínimo imprescindible de competencias en una serie de materias muy determinadas (coordinación, organización de acontecimientos deportivos de importancia nacional e internacional y la armonización, planificación y representación internacional del deporte nacional ), dejando el resto, por razones de mayor eficacia y operatividad, a las Comunidades Autónomas.

Cfr. la STC 1/1986, de 10 de enero.

(59) Véase en este sentido, Bermejo Vera, "El marco ...", cit. p. 20, nota 26; y Alonso García, op. cit., p. 1381, nota 18.

(60) Bermejo Vera, "Deportes", cit., p. 622.

(61) Cfr. arts. 9.24 del EAC y 44.19 de la LORAFNA. 
facultad de ordenar plenamente el asociacionismo deportivo en su ámbito territorial bajo el criterio del domicilio social coincidentes con el desarrollo principal de sus actividades asociativas. Su reconocimiento legal por la correspondiente Comunidad Autónoma se proyectará o tendrá eficacia en cuanto a la actividad deportiva -tomada como campo instrumental para la realización de los fines u objetivos de la asociaciónfuera de la Comunidad, en el ámbito estatal, previa la comunicación al 'órgano o registro estatal correspondiente (62). En otro caso no sólo se reduciría en exceso el uso de las competencias propias autonómicas, sino que significaría la división en compartimentos de estancos de España y la infracción del principio de libre circulación de personal y bienes (artículo 139.2 de la CE), derivándose una fragmentación ya criticada por el Tribunal Constitucional (63).

Así pues, admitiendo, desde las premisas expuestas, la competencia del Estado para regular determinados aspectos afectantes a la materia deportiva, podemos pasar a analizar la Ley 10/1990, del Deporte, desde la perspectiva autonómica, esto es, si dicha Ley a la luz del modelo estructural diseñado por la Constitución es adecuado o no para la consecución del orden sustantivo establecido por ésta.

5. Análisis de la Ley del Deporte de 1990.

La Ley del Deporte supone una mejoría desde la perspectiva competencial respecto de la Ley de 1980 , debida en buena parte a las mejores que, desde la óptica autonómica, se han introducido en el texto legal durante el iter parlamentario.

Así pueden mencionarse:

a) La integración participativa de las Comunidades Autónomas en órganos estatales (Comisión Directiva del Consejo Superior de Deportes, art. 10.1).

b) Las previsiones de actuación en colaboración con las Comunidades Autónomas: en cuanto al deporte de alto nivel (art.6.2); y en la actualización del censo nacional de instalaciones deportivas (art.8.n).

c) La prevista integración de las federaciones autonómicas en las Federaciones Españolas correspondientes, articulándose diversas previsiones en tal sentido (arts. 30.1 y 32.2).

d) La declaración de las Federaciones Autonómicas integradas en las españolas como entidades de utilidad pública (art. 44.1).

(62) Coincido en este punto con lo sostenido en el Dictamen del Consejo Consultivo de la Generalidad de Cataluña núm. 144, de 15 de marzo de 1988, ya citado.

A esta solución apunta la STC 15/1989, F.J. 7.

(63) Véanse las SSTC 37/1981, de 16 de noviembre, F.J. 1; y 44/1984, de 27 de marzo, F.J. 2. 
e) Especialmente, el nuevo inciso adicionado al artículo 32.4, sobre las licencias federativas (64), del siguiente tenor:

"Las licencias expedidas por las Federaciones de ámbito autonómico habilitarán para dicha participación (en competiciones deportivas oficiales de ámbito estatal) cuando éstas se hallen integradas en las Federaciones deportivas españolas, se expidan dentro de las condiciones mínimas de carácter económico que fijen éstas y comuniquen su expedición a las mismas".

Esta nueva previsión se sitúa en la línea más arriba auspiciada, de reconocer la plena competencia autonómica en materia deportiva, coordinándola (a través de la comunicación a los órganos y registros estatales) con la existencia de competiciones deportivas a nivel estatal e internacional, cuyos aspectos deportivos son regulados por el Estado.

La unicidad del deportista o del club conlleva que su legal constitución en el ámbito autonómico deba expandirse al total ámbito estatal, para evitar la fragmentación o separación territorial, facilitar la comunicación deportiva a todos los niveles y favorecer la consecución de los principios sustantivos constitucionales y deportivos.

f) La Disposición Adicional Quinta de la Ley prevé el reconocimiento legal de las asociaciones deportivas constituidas o inscritas en Registros autonómicos de acuerdo con la legislación autonómica correspondiente como Clubs deportivos a los efectos de dicha Ley. Aunque añade la exigencia de que «en sus Estatutos prevean la constitución, ajustados a principios democráticos, de Organos de Gobierno y representación y un régimen de responsabilidad de los directivos y socios".

Las anteriores consideraciones no nos relevan de poner de manifiesto algunos puntos conflictivos y discutibles desde la perspectiva autonómica de la Ley del Deporte:

a) Su propia denominación, que transluce una óptica de competencia general sobre la materia; cuando la perspectiva a consignar era precisamente la opuesta. El Estado carece de una competencia expresa y general sobre el deporte; ya que sus facultades se limitan a determinados eventos deportivos de ámbito estatal e internacional.

b) La generalidad, globalidad y ambigüedad de alguno de los preceptos incluídos en su Título Primero de "Principios generales", o bien comporta la afectación al ámbito competencial propio de las Comunidades Autónomas. o bien dota a la Ley de un cierto carácter armonizador.

En. tal título debió reconocerse o salvarse expresamente la competencia exclusiva de las Comunidades Autónomas, como por

(64) Con la consiguiente supresión del número 1 del art.47 del Proyecto, que resultaba contradictorio con esta nueva norma. 
alguna enmienda se propuso durante el procedimiento parlamentario.

c) La configuración de los Clubs que participen en competiciones deportivas oficiales de carácter profesional y ámbito estatal bajo la forma de Sociedad Anónima Deportiva, al margen de su idoneidad y de los problemas que plantea, motiva la exclusión competencial sobre ellos de las Comunidades Autónomas (65).

d) La Ley (art. 6.1 y Título VI) configura, por razones finalistas, el deporte de alto nivel como de la competencia estatal ("de interés para el Estado") (66); lo que colisiona con las previsiones de algunas leyes autonómicas del deporte.

Es preciso señalar, en palabras del Dictamen del Consejo Consultivo de la Generalidad de Cataluña núm. 50. de 20 de octubre de 1983 (F.J. IV), en relación con una norma de promoción en materia de turismo, que «no se puede confundir el objeto o acotación material de la competencia (turismo), que es la base para el establecimiento del orden competencial y para la atribución de titularidades, con las finalidades (promoción exterior) de la competencia que se proyectan en los actos de ejercicio de la misma. La conversión de los fines concretos de las decisiones administrativas en criterios para la definición de competencias implicaría una reformulación permanente del orden competencial que está reservado a la Constitución y a los Estatutos de Autonomian (67).

\section{REFLEXIÓN FINAL.}

La importancia y la pluralidad y diversidad de manifestaciones del fenómeno deportivo requieren la colaboración y cooperación entre las distintas instancias territoriales que intervienen en materia deportiva (68). Debe favorecerse su integración participativa fundamentalmente

(65) El título competencial, en este caso, del Estado parece ser la legislación mercantil (art. 149.1.6).

Pero téngase en cuenta el concreto significado de ese título, sobre todo cuando confluye con otros más especificos, de acuerdo con las SSTC 72/1983, de 29 de julio (F.J. 3) y 88/1986, de 1 de julio (F.J. 5).

(66) El artículo 6.1 dice asi: «1. El deporte de alto nivel se considera de interés para el Estado, en tanto que constituye un factor esencial en el desarrollo deportivo, por el estímulo que supone para el fomento del deporte base, en virtud de las exigencias técnicas y científicas de su preparación, y por su función representativa de España en las pruebas o competiciones deportivas oficiales de carácter internacionaln.

Véase la crítica de VIVER I PI-SUNYER, op. cit., p. 81, a las ponderaciones o criterios finalistas para justificar actuaciones estatales con nula o endeble base competencial.

(67) Dictámenes 1983, Barcelona, 1985. p. 187.

El conflicto de competencias a que se refiere este Dictamen fue resuelto por la STC 125/ 1984, de 20 de noviembre, en favor de la Generalidad de Cataluña.

(68) El particular y limitado objeto de este trabajo no impide reconocer el importante papel de las Entidades Locales en cuanto al deporte. 
en la fase ascendente, con una descentralización máxima en la vertiente ejecutiva. Este modelo de construcción participativa, con arreglo a criterios de colaboración y cooperación, sin olvidar el esquema delimitador competencial (69), debe alcanzar a la fase aplicativa, por cuanto que la fuerza y virtualidad de una norma legal no la da sólo su promulgación, sino sobre todo su efectividad social que habrá de acreditar la bondad material de la Ley.

Uno de los aspectos en el que ha de manifestarse el singular papel de las Comunidades Autónomas en materia deportiva es la faceta económico-financiera. La descentralización del gasto público en la materia que nos ocupa ha de convertirse en una plena y efectiva realidad, sin que nuevas normas estatales reformulen, caso por caso y mediante criterios finalistas, la delimitación constitucional y estatuaria de competencias en el plano económico (70).

Véase el trabajo de Alonso Garcia, citado en nota 8.

(69) Como propone VIVER PI-SUNYER, op. cit., pp. 93-101, deben elaborarse criterios objetivos y generalizables de delimitación competencial, desterrando el recurso a criterios finalistas u precisando el específico -y no tautológico-papel de la cooperación (cfr., en cuanto a esto último, p. 90).

(70) Es menester recordar la ya citada STC 75/89, FJ 3. Véase también la problemática y consideraciones expuestas por López Guerra, op. cit., pp. 60-63. 